\title{
Building a Proposed Mobile Learning Prototype for Egyptian Higher Education
}

Kholoud Farag.

Assistant Teacher, Dept. of Computer and Information Systems, SAMS

\author{
Dr. Hoda M. Wagih \\ Associate prof. Dept. of com- \\ puter and Information \\ Systems, SAMS
}

\author{
Prof. Mohamed \\ M. El Hadi \\ Dept. of Computer and \\ Information Systems, SAMS
}

\section{Abstract}

Mobile devices could facilitate human interaction and access to knowledge resources anytime and anywhere. Accordingly, this will change human-computer interaction, communication, and learning activities. So, computing devices have become common place on today's college campuses in the Egyptian higher education.

From notebook computers to wireless phones and mobile devices, the massive infusion of computing devices and rapidly improved Internet capabilities have the power to alter the nature of higher education. Consequently, mlearning is to enhance collaboration sharing among learners. Teaching and learning processes are concerned with the creation and ongoing development of skills within a group of learners. Furthermore, M-learning is to be developed as a way to ensure that learnings reaches the right learner at the right time.

So, the ability to support students/learners to learn on the move at any place and at any time is a new task to be addressed by using the mobile devices of the learners. Mobile technology support has given birth to the concept of mobile learning possessing a wide spectrum of applications and new teaching and learning techniques. This paper discusses a study conducted for undergraduate students on the effect of mobile technology usage in a learning process. The results here indicate acceptance of the mobile devices into the learning process with a well appreciated enthusiasm from the learners.

Keywords: M-learning, Egyptian Higher Education.

\section{1-Introduction}

In today's society, students have access to handheld technologies that are more powerful and better connected than conventional desktop computers. These technologies not only provide students' access to the internet but also serve as a mechanism for what has become their main mode of electronic communication: e-mail and instant messaging.

As a result of increased popularity, this phenomena and demand of mobility has extended to the teaching and learning environment. So, with the start of the new millennium, the development and delivery of mobile learning has grown in a visibility and significance as witnessed by the number of research projects and dedicated conferences and seminars. In any case, the concept of mobile learning is still emerging; therefore, researchers and educators alike are struggling with defining mobile learning in terms that are educationally relevant (Sarrab, M., Al-Shihi, H., \& Rehman, O. M. H.2013). In many respects, mlearning is a new concept that has familiar connotations. Similar to distance or eLearning, mlearning takes the learning process away from the four walls of a classroom. What makes m-Learning different is that it allows further breakout. Mlearning is the marriage between mobile computing, wireless computing, communication devices and e-learning (Oller, 2012).

Finally, the learning activities should be meaningful as well as teachers have to provide adequate learning technology for learning activities so that students can easily benefit from the mlearning process. (Liaw, S.,2011).

\section{2-Research framework}

\subsection{Objectives of the research paper}

Deployment of new emerging technologies have attracted and motivated a great deal of attention from researchers to 
investigate the learning process. So, the main objectives for this paper are:

a- Examining the important elements that will affect the students' usage of the mobile learning in higher education.

b- Exploring how should teachers understand the needs of mobile learning so that they can improve the educational services.

\subsection{Problem statement}

Widespread availability of mobile devices and wireless networks offer enormous opportunities for knowledge acquisition both in terms of interaction with sources of information and in terms of collaboration.

The question remains, however, as to whether M-Learning is as effective as face to face. Face to face is the delivery method that has traditionally been, and will most likely continue to be. It is therefore important and practical to evaluate the new M-Learning paradigm against face to face.

\subsection{Previous studies}

Riley, D. (2011) suggested one of the first examples of initiatives that gave rise to the recognition of mobile learning as a distinct phenomenon was Apple Computer's MessagePad PDA released in 1993 that ran the Newton operating system. In a review of the literature on mobile learning, the exact origin of the term could not be pinpointed. However, the first extensive use of mobile learning as a label for learning through the use of mobile devices surfaced in several pan-European mobile learning projects that started in the late 1990s and the early 2000s (Keegan, 2012). At the time, a consensus on a single definition of the term mobile learning does not appear to be evident in the relevant literature.

Also, Motiwalla (2011) argued mobile learning is a teaching and learning mode that is still in its earliest stages of development. It is this beginning status to which attributed the fact that in the literature no consensus on an accepted framework of dimensions and characteristics is evident. (Trinder, J., Magill, J., \& Roy, S., 2015) contended the rapidity with which changes and advancements in mobile learning are taking place. Also, is contributing to the lack of a universally-accepted list of components and attributes related to mobile learning.

\subsection{Methodology}

The methodology is divided into the following scientific methods:

2.4.1 Survey Method:
- Quantitative research method is used to survey student's behaviors, attitudes, and intention approach.

- Model building is suggested as an artifact for developing mlearning applications.

\subsubsection{Data gathering techniques:}

The following techniques were to be used for data gathering:

- Literature search.

- Questionnaires which surveys and reviews the existing is directed to students that are to be of a sample.

\subsubsection{Procedures of the research}

- Questionnaires validation and distribution:

The validation of the questionnaire is being done by consulting 10 local referees, as well as 12 foreign referees by e-mail via the search engines of Academia and Research Gate. The research sample is (160) students. The researcher selected (30) students form each department from the three different Egyptian universities.

- Data analysis

The survey aims to evaluate the actual need for the mlearning in higher education and consequently to be generalized as a new educational trend. The methodology of research employed was through a questionnaire. Statistical data and reports were also obtained. The data collected was processed and statistically analyzed through SPSS.

\subsection{The main hypotheses for this research:}

The main hypothesis stated that there is a significance effect between independent variables (Development of $M$ learning, Staff involvement, Software availability, Ease of use, User satisfaction, Attractiveness, Learnability) and the dependent variable ( Mobile learning Activities, Students attitudes to M-learning.) at level of significance $\infty=0.05$.

\section{3- Questionnaires' Responses Analysis:}

The researcher selected (30) students form each department from the three different universities; Faculty of Education, Educational Technology department, Helwan university, Faculty of computers and information (Information system and Information technology department), Helwan university, Faculties of Computers and Information in Cairo university (Information system and Information technology department) as well as Faculty of computers and information system, Ain Shams University (Information system department). The sample is 160 students. The actual audience who respond to the questionnaire are (138) students from all 
the departments in the three different universities. The following chart represent the audiences' responses.

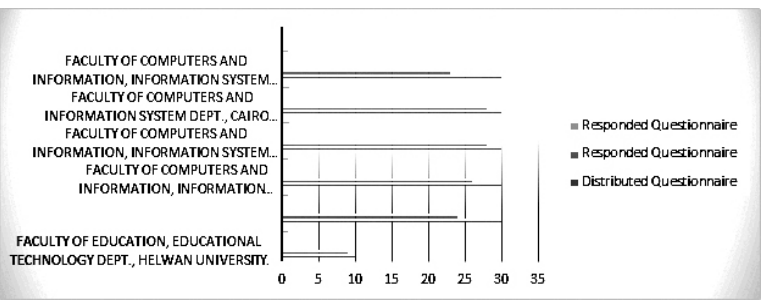

Figure1: Audiences' responses.

The previous chart clarifies the responses from the previously mentioned sample. It determines the responses in each department for each faculty. The chart shows that most of the audience responded to the questionnaire, which is acceptable to depend on for the required analysis.

\subsection{Responses' b Analysis Features}

\subsubsection{Analysis's statistical techniques:}

These are the techniques used to study the relationship between the dependent and the independent variables. They are; Pearson correlation coefficient for Validity, analysis of Variance (ANOVA), the One-Way Analysis of Variance (ANOVA) and the test statistic (One-sample T).

\subsubsection{The main topics of the questionnaire:}

The designed questionnaire has been updated according to the referees' comments and instructions. The following is the main topics agreed upon and filled by the previously mentioned sample.

\subsubsection{Mobile Devices:}

This section investigates the availability and the specifications of the mobile devices that the user has access to it. The results indicated the availability of smart mobile devices with compatible specification to the needs of the mlearning.

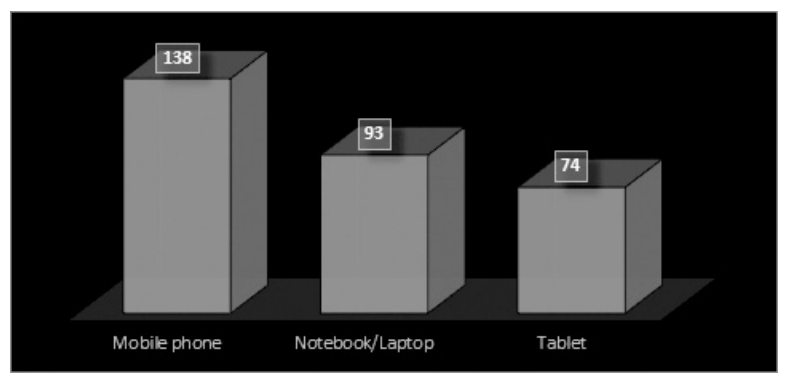

Figure2: Mobile devices.

This chart shows the percentage of the availability of mobile devices among the audience in the different faculties. It seems that it is acceptable to enable the mlearning as most of them have the needed device.

\subsubsection{Mobile learning software:}

This section describes the availability of the software for the M-learning to allow collaboration and users' interaction. It also investigates the ability to develop educational service and being able to study in places they couldn't normally study in it.

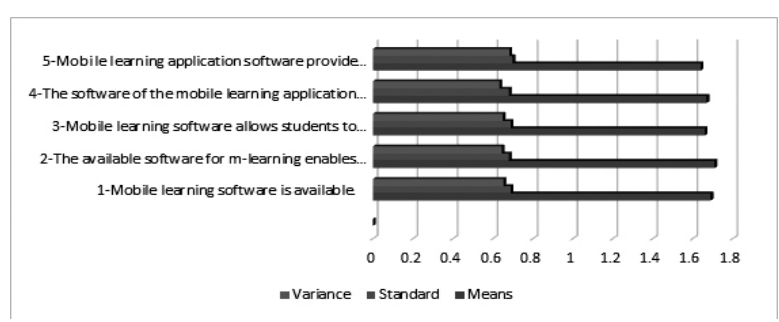

Figure3: Mobile learning software

The chart represents the variance, standard deviation and the means for the mlearning software. It shows that the means for availability of the software is very high as it reaches the level of 1.7 which is considered very acceptable. also, the standard deviation $<1$. This indicates the maximum availability of mlearning software.

\subsubsection{3: Mobile Learning in Education:}

Mobile learning in Education consists of (3) items. It is concerned with the ability to evaluate and access the mobile technology. It also asks about the intention for participation in the electronic learning activities.

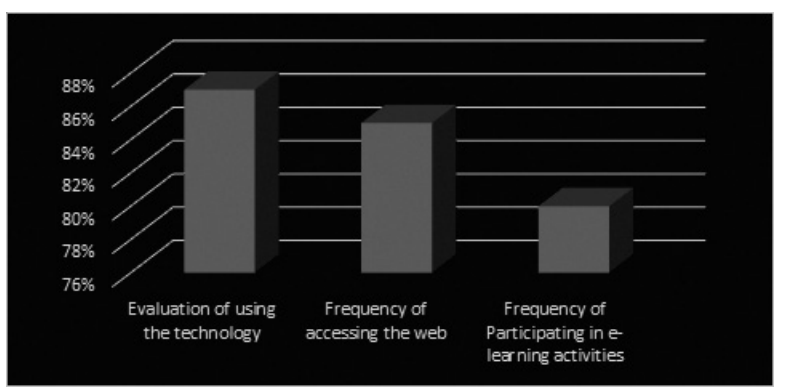

Figure 4: Mobile Learning in Education

The Mobile learning in education chart identifies the frequency and the percentage of participating and accessing the web. The percentage exceeds the $80 \%$ which highly recommend the using of mlearning in education.

\subsubsection{Mobile Learning Activities:}

This section clarifies the importance of m-learning in enhancing the overall quality of education. It also discusses the ability for content retrieval and the content structure which enable online courses. 


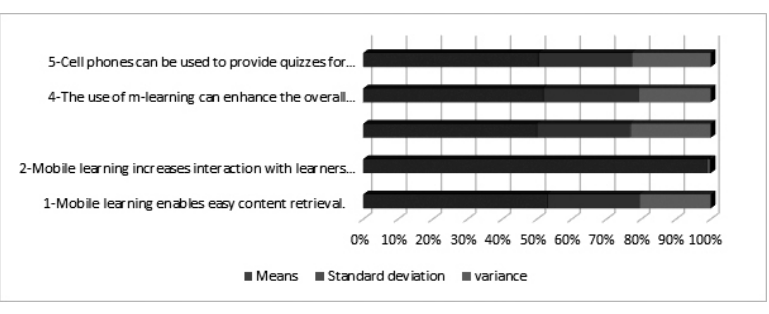

Figure 5: Mobile Learning Activities

The chart assures that the learning activities is essential. The percentages are high regarding the whole activities for enhancing the overall quality of education. The increase in the means indicates the increase in the interaction with learners and content retrieval.

\subsubsection{M-Learning Security:}

This section cares about the overall security for all the activities in the mlearning regarding the online exams, quizzes, password prompt and the user management for his account. It also concerns with what the user submits for his work and assignments.

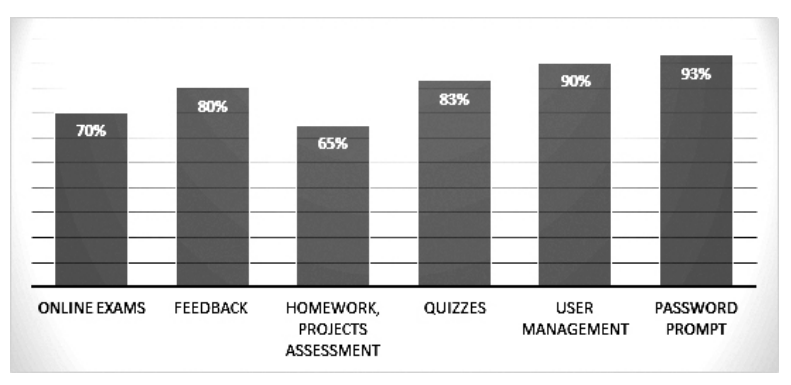

Figure 6: Mobile learning security

The previous chart is concerned with the security aspects. This includes all the actions taken by the learner to enable the mlearning process to take place. The audience of the sample choices gave us these percentages for the security aspects. The highest percentage is the password prompt as it reaches $93 \%$ which is highly important to save the learners' credentials. This percentage is followed by user management $90 \%$, feedback $80 \%$ and online exams $70 \%$.

\subsubsection{Students Attitudes towards Mlearning:}

This item states all the needed actions to enhance students' attitudes towards mlearning. It describes the availability of cell phone to be incorporated into classes and how it is familiar for the students to use it with all its functions.

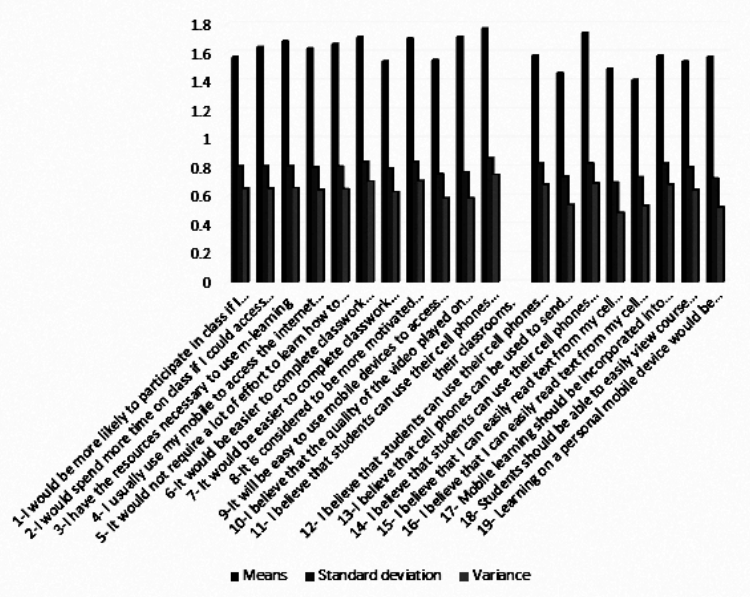

Figure 7: Students Attitudes towards M-Learning

The previous chart represents the attitudes of the audience towards the attitudes of the learners in the mlearning. All the means, standard deviations and the variance regarding all the attitudes from the learner side. The means recorded $>1$ which indicates that the attitude has the intention to accept mlearning in a wide range.

3.2.2.7 Student Perceptions about Staff Members Involvement in m-Learning, and for Mobile Development Involvement in M-Learning Development:

This item is the section which help in understanding the acceptance of the staff member to the mlearning and their intentions to incorporate mlearning application into the educator's instruction.

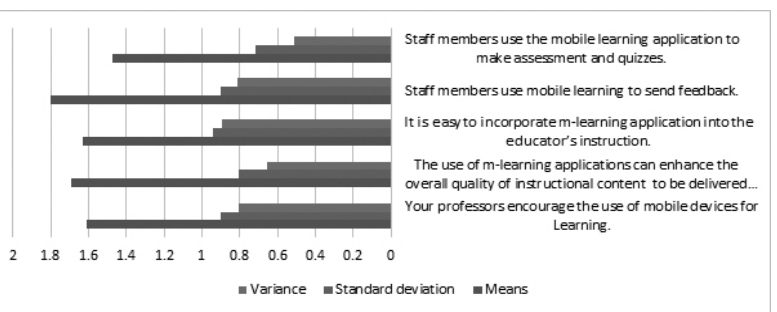

Figure 8: Student Perceptions about Staff Members Involvement in m-Learning, and for Mobile Development Involvement in M-Learning Development

According to this chart, it is obvious that the means reaches the 1.8 which encourage using the mlearning for sending feedback. Also, enhancing the overall quality of instructional content to be delivered to the students.

3.2.2.8 Students Perception for Mobile Learning Development:

This section illustrates the required items for motivating the development of the educational structure creation. It 
also states the improvement required in the interface to allow content access anywhere and anytime.

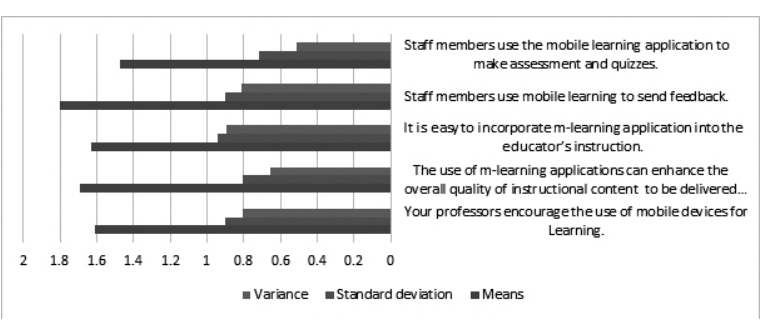

Figure 8: Student Perceptions about Staff Members Involvement in m-Learning, and for Mobile Development Involvement in M-Learning Development

According to this chart, it is obvious that the means reaches the 1.8 which encourage using the mlearning for sending feedback. Also, enhancing the overall quality of instructional content to be delivered to the students.

3.2.2.8 Students Perception for Mobile Learning Development:

This section illustrates the required items for motivating the development of the educational structure creation. It also states the improvement required in the interface to allow content access anywhere and anytime.

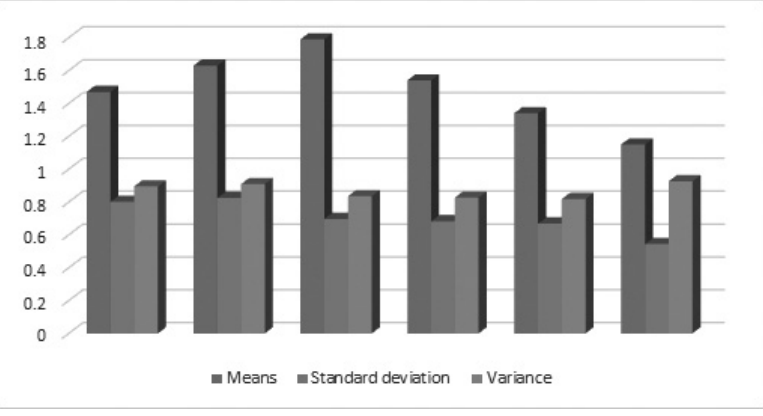

Figure 9: Students Perception for Mobile Learning Development

The students' perception chart assures their acceptance for using the mlearning process as the means is $>1.5$ and approximately reaches 2 . This means an overall perception about the mlearning development and their intention to use it.

\subsubsection{Usability of M-learning:}

It consist of four sections as the follows:

- Ease of use. It consists of (5) items.

It means the easiness to navigate and to scan the learning content application to find the wanted information

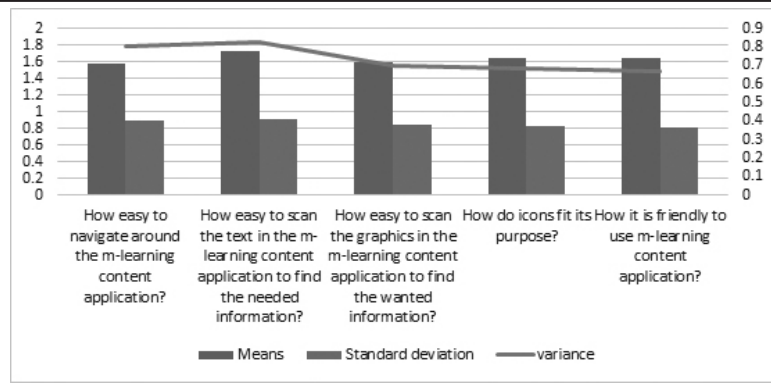

Figure 10: Ease of use

The previous chart concerns with the easiness of using the mlearning from the perspectives of being able to navigate, to scan and being able to use the content easily. The means represented in the chart has an acceptable rate as it reached 1.8, which indicates the ease of use.

- User satisfaction. It consists of (3) items

It concerns with the ability to be familiar to the different available functions in the application. And that the content provides enough suggestions towards the right usage.

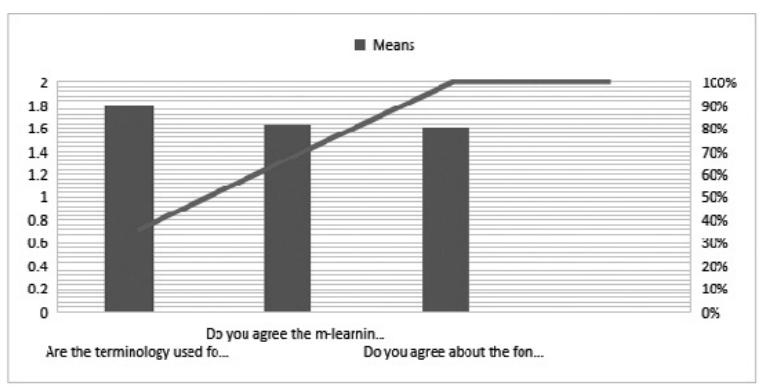

Figure 11: User Satisfaction

One of the most important charts is the user satisfaction to enable the mlearning. The chart represents the degree of satisfaction. It seems from the chart that the mlearning user satisfaction reaches near the $90 \%$ with correspondence to the means that reaches 1.8 . This is a high rate to be highly accepted as it enables the user satisfaction.

- Attractiveness. It consists of (3) items.

It the idea of having some sort of suitable design from the perspective of the colors and graphics to be clear and at tractive

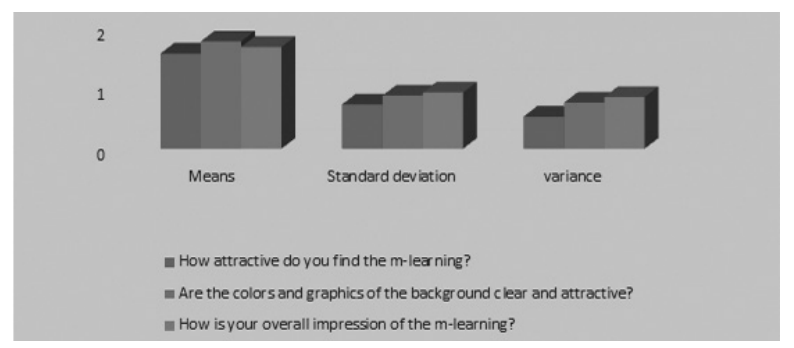

Figure 12: Attractiveness 
The attractiveness chart identifies the overall impression of the m-learning. From the chart it is obvious that the means is high regarding the overall attractiveness as it registers for the means 1.5, and registered 2 for the graphics need and the background used. Also the overall impression to use it as a way for enhancing education registered 1.67 . while the variance and standard deviation register low rates.

- Learnability. It consists of (3) items.

It describes the ability to understand the hierarchical of the program to enable operating the system easily to gain benefit from it.

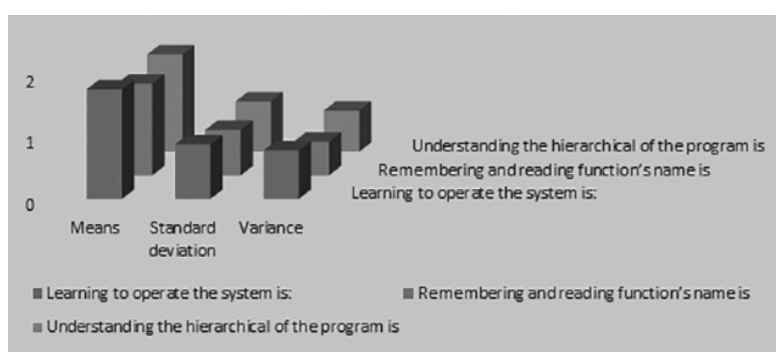

Figure 13: Learnability

The previous chart represents the means, variance and the standard deviation for the learnability concerning three aspects. The ability to understand the hierarchal of the program, the ability to use the program functions and to operate the system registering approximately 2 . The means for them is a high rate while the variance and the standard deviation is approximately< than 1 .

\section{4- Hypotheses Testing}

This is to test the relationship between the dependent and the independent variables of the research.

In order to test the fields of research tool (questionnaire), and paragraphs analysis, parametric tests will use: Onesample T test, T-test and Analysis of Variance- ANOVA.

Null hypothesis: H0: $\mu 1=\mu 2 \quad$ The two audiences' means are equal

Alternative hypothesis: $\mathrm{H} 1: \mu 1 \infty \mu 2$ The two audiences' means are not equal

From the main hypothesis the following sub hypotheses result:

a) There is a statistical significant relation between Development of M-learning in the Egyptian Higher Education and the adoption of mobile learning activates (at the level of significance $\infty=0.05$ ).

b) There is a statistical significant relation between Staff involvement and the adoption of mobile learning activates (at the level of significance $\infty=0.05$ ).

c) There is a statistical significant relation between Ease of use and Students' attitudes to M-learning (at the level of significance $\infty=0.05$ ).

d) There is a statistical significant relation between user satisfaction and Students' attitudes to M-learning (at the level of significance $\infty=0.05$ ).

e) There is a statistical significant relation between Attractiveness and Students' attitudes to M-learning (at the level of significance $\infty=0.05$ ).

f) There is a statistical significant relation between Learnability and Students' attitudes to M-learning (at the level of significance $\infty=0.05$ ).

5- Conclusion

\subsection{Results}

The descriptive statistical analysis for the means, standard deviation and variance for each part in the questionnaire indicated the following results:

1. The majority of the respondents preferred using the mobile technology in promotion of distance learning.

2. There is a significant relationship between the adoption of mobile learning and the independent variables at level of significance $\infty=0.05$.

3. Also shows that the students agreed that mobile phones had successfully enhanced the teaching and learning process.

4. The analysis of the questionnaire leads to the fact that students is widely accepted the perception of mobile learning the students support the idea.

5. It increases the flexibility of accessing to the resources and also can access information any time anywhere.

6. Mobile learning is a flexible method than traditional learning and can access easier to the sources of learning any time anywhere.

7. It is a must to encourage the adoption of mobile learning. This requires ongoing development of mobile learning technology and the importance of its use.

8. Mobile learning technology is an attractive technology as it enables more collaboration and learnability.

9. It's recommended for the educational sector to have plans to get rid of obstacles that hinder the use of any new technology.

10. It's necessary to provide the support and the needed requirements to adopt mobile learning technology in the 
Egyptian higher education.

11. Mlearning is possible through properly coordinated efforts of the institution, teachers and the learners.

12. The questionnaire's indicated that M-learning can maximize education on demand. With the ability to access educational materials at any time and any place, mobile technology makes educational resources more readily available and accessible. Therefore, students can gain access to educational resources based on their personal needs and preferences.

13. The student participation inside and outside the classroom would increase if students could use mobile devices in the classroom.

14. Results also reveal that students would be more engaged in class discussions inside the classroom if they could use devices and would be more engaged both inside and outside the classroom if students could use devices to post responses.

15. Students indicated that the use of mobile devices would allow them to spend more time on classwork and that they would be more likely to ask for help if they could communicate through their mobile devices.

\subsection{Recommendations}

Based on the results of this study, the following recommendations are offered to support the effective use of mobile technology in learning:

1) Increased faculty training regarding the capabilities of mobile technology and the potential use in the classroom including applications that are available via smartphone stores and textbook companies.

2) Resource page on the university website with recommendations for mobile applications that may be applicable to students and faculty.

3) Increased dialogue among students and faculty, faculty and faculty, and faculty and administrators about the learning opportunities available through mobile devices.

4) Formation of a partnership with a mobile network that reduces the cost of a device and/or data plan for students and faculty.

5) Integrating the mobile use into the university curriculum by blending this technology with curriculum text books and syllabi.

6) Holding training courses for students and faculty members in using the mobile phone in university education and to acquire more experience in this field.
7) Implementation of mobile learning applications in some target fields must take into consideration the availability of IT technology.

8) Investigating different online educational strategies which help in better ways of understanding and learning.

9) Developing new methods for more interaction via the net using the different mobile learning capabilities.

\subsection{Future work}

There are several studies and future works that could be constructed in the field of mobile learning as follows:

1- Future research can be conducted with $\mathrm{K}-12$ students and instructors to determine whether their values of mobile applications in education differ from those of the university settings, and if so, identify the specific factors that contribute to such differences. In this way, potential mobile applications for these settings can be proposed.

2- Future research may want to include multiple institutions and examine differences based on region and available resources.

3- Additional research could also be done to include graduate students and compare the perceptions of undergraduate and graduate students however, future research with undergraduates may also be problematic due to the number of students who change majors from junior to senior year.

4- Researchers may also want to further investigate factors that affect student and faculty attitudes and perceptions. It was necessary to investigate the attitudes and perceptions of large sample to add to the current research.

5- In collaboration with researchers from other fields, future researchers may also want to enable instructors to easily develop content specific applications.

6- Future research should also further develop mobile learning theory as it relates to current technology and best practices so that mobile learning may be able to acquire its own identity separate from e-learning.

7- Also, no other existing study to date has conducted a regional analysis of $\mathrm{m}$-Learning use among community college faculty members.

8- Future studies might examine more specific questions about the most frequently used strategies, or possibly the least frequently used strategies.

9- Topics could include methods of assessment, student training, or management techniques when using multi-platform devices.

10- Investigative comparisons about $\mathrm{m}$-Learning percep- 
tions among IT managers, academic administrators, or even presidents might be an important area of inquiry.

11- Lastly, there is a need to conduct additional research about mobile skills in the workplace.

12- Specifically, future research might target the expectations of business and industry in regards to the mobile competence of recent community college graduates.

13- Since community colleges have rooted their reputations in being responsive to business and industry, it may be useful to know how extensively graduates are expected to be comfortable with mobile devices or $m$-Learning strategies as they enter the workplace. If there is a growing need, such investigations could give birth to extended partnerships or support from business and industry for training and resources.

14- Actually, future studies could offer more extensive analysis of specific disciplines and their use of $m$-Learning.

15- Further research studies are recommended to identify the obstacles which encounter the mobile phone usage in university education from the perspectives of the faculty members.

\section{6-References}

1. Liaw, S.,(2011). Developing a Web assisted knowledge construction system based on the approach of constructivist knowledge analysis of tasks. Computers in Human Behavior.

2. Keegan, D. ,2012.The future of learning: From elearning to mlearning. Retrieved April 24, 2015, from the ERIC Document Service ED 472435.

3. Motiwalla, L. F. (2011). Mobile learning: Aframework and evaluation. Computers \& Education,49(3), 596.

4. Riley, D. (2011). "Educational Technology and Practice: Types and Timescales of Change." Educational Technology \&Society 10: 85-93

5. Oller, R., (2012). The future of mobile learning (research bulleting). EDUCAUSE Center for Applied Research. Retrieved from http://www.educause.edu/ecar.

6. Sarrab, M., Al-Shihi, H., \& Rehman, O. M. H. (2013). Exploring major challenges and benefits of $\mathrm{m}$-learning adoption. British Journal of Applied Science and Technology, 3(4), 826-827.

7. Trinder, J., Magill, J., \& Roy, S., 2015. Expect the unexpected: Practicalities and problems of a PDA project. In A. Kukulska-Hulme \& J. Traxler (Eds.), Mobile learning: A handbook for educators and trainers. London: Routledge.

\section{What are the $21^{\text {st }}$-Century Skills Every Student Needs?}

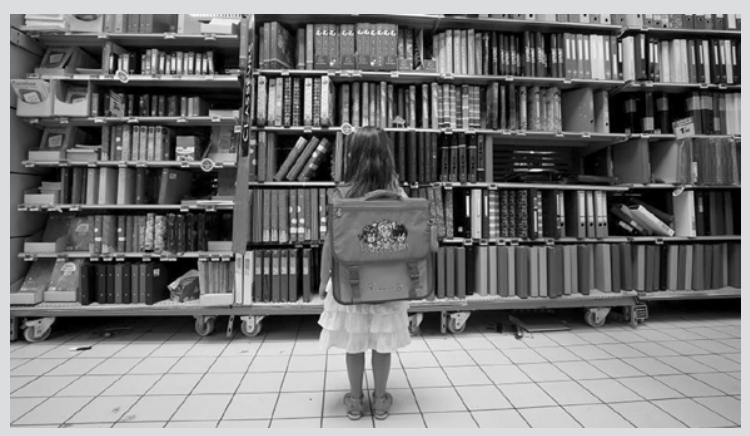

More on the agenda The gap between the skills people learn and the skills people need is becoming more obvious, as traditional learning falls short of equipping students with the knowledge they need to thrive, according to the World Economic Forum report New Vision for Education: Fostering Social and Emotional Learning Through Technology.

Today's job candidates must be able to collaborate, communicate and solve problems - skills developed mainly through social and emotional learning (SEL). Combined with traditional skills, this social and emotional proficiency will equip students to succeed in the evolving digital economy.

What skills will be needed most?

An analysis of 213 studies showed that students who received SEL instruction had achievement scores that averaged 11 percentile points higher than those who did not. And SEL potentially leads to long-term benefits such as higher rates of employment and educational fulfillment.

Good leadership skills as well as curiosity are also important for students to learn for their future jobs.

Another Forum report, The Future of Jobs, launched during the Annual Meeting 2016 in Davos, looked at the employment, skills and workforce strategy for the future.

The report asked chief human resources and strategy officers from leading global employers what the current shifts mean, specifically for employment, skills and recruitment across industries and geographies.

Policy-makers, educators, parents, businesses, researchers, technology developers, investors and NGOs can together ensure that development of social and emotional skills becomes a shared goal and competency of education systems everywhere. 